\title{
Low intensity training improves redox status and reduces collagen fibers on dystrophic muscle
}

\author{
Danielle Cristina Fernandes', Jessica Junia A. Cardoso-Nascimento', Bruna Caroline C. Garcia², Karine Beatriz Costa ${ }^{2}$, \\ Etel Rocha-Vieira², Murilo Xavier Oliveira', Alex Sander D. Machado², Ana Paula Santos', Thaís Peixoto Gaiad ${ }^{1}{ }^{1 *}$ \\ 'Department of Physical Therapy, Post Graduate Program of Rehabilitation and Functional Performance, Universidade Federal dos Vales do Jequitinhonha e Mucuri, \\ Diamantina, Brazil \\ ${ }^{2}$ Post Graduate Program in Physiological Science, Brazilian Society of Physiology, Universidade Federal dos Vales do Jequitinhonha e Mucuri, Diamantina, Brazil
}

Exercise therapy on skeletal muscle of muscular dystrophies has no defined parameters. The effect of low-intensity treadmill training on the oxidative stress markers and fibrosis on hindlimb muscles was investigated. Sixteen dystrophic male $m d x$ animals were separated in trained $(m d x T / n=8)$ and untrained $(m d x N T / n=8)$ groups. Wild type animals $(\mathrm{WT} / \mathrm{n}=8)$ were used as healthy control. The $m d x T$ group runned at a horizontal treadmill ( $9 \mathrm{~m} / \mathrm{min}, 30 \mathrm{~min} /$ day, 3 times/wk, 8 weeks). Gastrocnemius and tibial anterior muscles were collected for analysis of enzymatic/non-enzymatic oxidant activity, oxidative damage concentration, collagen fibers area morphometry. The $m d x T$ group presented a lower collagen fiber area compared to $m d x$ NT for gastrocnemius $(P=0.025)$ and tibial anterior $(P=0.000)$. Oxidative damage activity was higher in the $m d x T$ group for both muscles compared to $m d x$ NT. Catalase presented similar activity for tibial anterior $(P=0.527)$ or gastrocnemius $(P=0.323)$. Superoxide dismutase $(P=0.003)$ and total antioxidant capacity $(P=0.024)$ showed increased activity in the $m d x T$ group at tibial anterior with no difference for gastrocnemius. Low-intensity training is considered therapeutic as it reduces collagen deposition while improving tissue redox status.

Keywords: Duchenne muscular dystrophy, Exercise, Fibrosis, $m d x$ mouse, Redox status

\section{INTRODUCTION}

Duchenne muscular dystrophy (DMD) is a genetic disease caused by the absence of dystrophin protein which promotes sarcoplasmatic membrane stability (Comim et al., 2016; Kostek and Gordon, 2018). Its absence makes skeletal muscle susceptible to contraction-induced injuries (Schill et al., 2016; Van Putten et al., 2012), as well as weakness and muscle loss (Gianola et al., 2013), with muscle tissue showing a chronic inflammatory feature (Mann et al., 2011).

Inflammation is an early event in DMD which leads to an excessive influx of electrolytes in the form of calcium and sodium. The accumulation of acidic metabolites and the increased inflammatory substances lead to muscle fibers apoptosis, necrosis and to degeneration/regeneration cycles. Over time, there is a reduction in the regenerative capacity of muscle fibers and an accumulation of collagen fibers in the extracellular matrix resulting in fibrosis and generating weakness in the diaphragm and limb muscles (Kim et al., 2013; Klingler et al., 2012; Kostek and Gordon, 2018; Smith et al., 2016).

In DMD, this microenvironment of regeneration without synchrony is exacerbated by inflammatory cytokines and by oxidative stress, frequently associated with the fibrogenesis process (Barbieri and Sestili, 2012; Chazaud, 2016; Mann et al., 2011; Zanotti et al., 2016). Redox equilibrium is essential for cellular homeostasis (Pérez-Torres et al., 2017), being a key modulator of skeletal muscle plasticity/dysfunction (Espinosa et al., 2016). Oxidant enzymes can interfere with skeletal muscle fibrosis deposition progression (Kozakowska et al., 2015) showing efficacy on dystrophic phenotype improvement, reducing muscle damage, loss of muscle
${ }^{*}$ Corresponding author: Thaís Peixoto Gaiad (iD https://orcid.org/0000-0002-4688-330X Department of Physical Therapy - Universidade Federal dos Vales do Jequitinhonha e Mucuri (UFVJM), Rod MGT 367 - km 583, n 5000, CEP: 39100-000-Diamantina, MG, Brazil

E-mail: thaispgm@gmail.com

Received: February 2, 2019/ Accepted: March 23, 2019
This is an Open Access article distributed under the terms of the Creative Commons Attribution Non-Commercial License (http://creativecommons.org/licenses/by-nc/4.0/) which permits unrestricted non-commercial use, distribution, and reproduction in any medium, provided the original work is properly cited. 
strength, inflammatory process and fibrosis (Comim et al., 2016).

In a systematic review, elaborated by Hyzewicz et al. (2015a) whose sample includes 16 studies in horizontal treadmill, only $25 \%$ used low-intensity training $(9 \mathrm{~m} / \mathrm{min})$, demonstrating the positive effects in the physiological parameters of the $m d x$ model. Rota-rod (Frinchi et al., 2014), swimming (Hyzewicz et al., 2015b) and horizontal treadmill (Gaiad et al., 2017) are modalities of low-intensity training and authors observed improvement on mitochondrial gene expression, muscle differentiation on degeneration/regeneration process and turnover of extracellular matrix of the skeletal dystrophic muscle.

Low-intensity training has been seen as a promising form of treatment. Oxidative stress, in addition to damaging cell structures, can interfere with the inflammation/regeneration process of muscle fibers, resulting in fibrosis that impairs muscle function. These two parameters can help us clarify the role of low-intensity training on the dystrophic muscle. We tested the hypothesis that lowintensity training leads to adaptation of antioxidant enzymes reducing deleterious effects of reactive oxygen species (ROS) produced during exercise training leading to a reduced fibrosis deposition on skeletal muscle of the $m d x$ model.

\section{MATERIALS AND METHODS}

\section{Experimental design}

Sixteen male $m d x$ mice (C57BL/10ScSn-Dmd $m d x / \mathrm{J})$ and eight wild-type mice (C57BL/10) acquired from the FioCruz Institute (Rio de Janeiro, Brazil) were used in this study. This research was approved by the Ethics Committee on Animal Use of the Universidade Federal University of Vales do Jequitinhonha e Mucuri under protocol $n^{\circ}$ 017/2011. Animals were maintained in cages under $12 \mathrm{hr}$ day/night cycle, $22^{\circ} \mathrm{C}$, supplied with food and water ad libitum Animals were aleatory randomized in two groups: trained group ( $m d x \mathrm{~T}, \mathrm{n}=8)$ and untrained group $(m d x \mathrm{NT}, \mathrm{n}=8)$. Wildtype (WT) mice composed the control group $(n=8)$. Exercise protocol started when animals were 11 weeks old. At this age fibrosis and muscle lesion are similar between $m d x$ mice and age-matched humans. (Grounds et al., 2008).

\section{Low-intensity training protocol}

A low-intensity training protocol on a horizontal treadmill (EP 131; Insight, Ribeirão Preto, Brazil) $30 \mathrm{~min} /$ day, 3 times a week for 60 days at a velocity of $9 \mathrm{~m} / \mathrm{min}$ were performed by the animals of the $m d x \mathrm{~T}$ group. The speed of the protocol was of $9 \mathrm{~m} /$ min so that the therapeutic training was considered low intensity
(De Luca, 2014). The animals of the $m d x$ NT group were placed on the off treadmill $(0 \mathrm{~m} / \mathrm{min})$ with the same duration and frequency as the animals of the $m d x \mathrm{~T}$ group to cause the same environmental stimuli to all mice.

\section{Biological sample collection}

After 8 weeks of low-intensity training protocol, samples of the tibial anterior and gastrocnemius muscle of all 3 groups ( $m d x \mathrm{~T}$, $m d x \mathrm{NT}$, and WT) were gathered for morphological, histochemical and redox status analysis. Muscle samples of the right hindlimb of approximately $2 \mathrm{~cm}^{2}$ were fixed in a paraformaldehyde solution at $4 \%$ to further histological and histochemical analysis. Muscle samples of the left hindlimb were immersed in a phosphate buffer $\mathrm{pH} 7.2$ to wash and stored at $-80^{\circ} \mathrm{C}$ for redox status markers assays.

\section{Histological and histochemical analysis}

The muscle samples of tibial anterior and gastrocnemius were fixed in paraformaldehyde solution and were processed to be embedded in paraffin. Sections of $5 \mu \mathrm{m}$ in thickness were obtained and were oven-dried $\left(60^{\circ} \mathrm{C}\right)$ in a horizontal position. Slides were reacted with Picrossirius red, a combination of Sirius red F3BA (Colour Index 35780, Sigma-Aldrich, St. Louis, MO, USA) dissolved in a saturated picric acid solution. Photomicrographs were made using an optical microscope (LABOMED LxPol, Labo America, Fremont, Canada) coupled to with an Axio CAM HRc camera and Software Capture Pro 2.9.0.1.

\section{Intramuscular collagen deposition}

Slides reacted with picrossirius red to exhibit collagen-positive areas from fifteen randomly selected fields $\times 100$ per animal ( 2.000 fibers/group) were quantified (Smith and Barton, 2014). The images were analyzed using ImageJ software (ver. 1.50i, National Institute Health, Bethesda, MD, USA), with a threshold was applied to each image, first converting it to 8-bit (blue), then subtracting the background and images automatically scaled from 0 to 255 . Intramuscular collagen analysis are shown in percentage of the total area $\left(964,819.05 \mu^{2}\right)$.

\section{Redox status markers}

Samples were macerated for 3 min (Corning, Potter-Elvehjem Tissue macerator) maintained on ice in PBS $(0.05 \mathrm{M}, \mathrm{pH} 7.34$, $4^{\circ} \mathrm{C}$ ). The homogenate was divided into two parts and one part was centrifuged (Thermo Electron Led GmbH D37520 Osterode, Kalkberg, Germany) at $5.000 \mathrm{~g}$ for $5 \mathrm{~min}$ at $4^{\circ} \mathrm{C}$ and was ana- 
lyzed on the basis of thiobarbituric reactive substances and the total antioxidant capacity (ferric reducing ability of plasma, FRAP) method. The sediment was used to measure the carbon content in proteins. The second part was centrifuged at $10.000 \mathrm{~g}$ for $10 \mathrm{~min}$ at $4^{\circ} \mathrm{C}$ and was used to analyze the activity of superoxide dismutase and catalase enzymes. All analyzes were performed in duplicates.

\section{Lipid peroxidation}

Thiobarbituric reactive substances concentration was measured in the muscle according to the method described Ohkawa et al. (1979). Aliquots of the tibial anterior and gastrocnemius samples $(0.15 \mathrm{~mL})$ were added to $8 \%$ sodium dodecyl sulfate, $2.5 \mathrm{M}$ acetic acid $(\mathrm{pH}, 3.4)$ and $0.8 \%$ thiobarbituric acid. The samples were incubated for $90 \mathrm{~min}$ at $95^{\circ} \mathrm{C}$ and read on a spectrophotometer at 532 nm (SpectraMax 190, Molecular Devices, San Jose, CA, USA). The concentrations of thiobarbituric reactive substances in the samples were determined from the standard curve of known concentrations of malondialdehyde (MDA) and expressed in nmol $\mathrm{MDA} / \mathrm{mg}$ protein.

\section{Carbonyl derivatives in proteins}

The tibial anterior and gastrocnemius homogenate pellet was suspended in $1 \mathrm{~mL}$ of $50 \mathrm{mM}$ potassium phosphate buffer $\mathrm{pH} 6.7$ containing $1 \mathrm{mM}$ ethylenediamine-tetra-acetic acid. Each sample was homogenized and divided in to blank and test. Ten percent of trichloroacetic acid was added to all samples which were then centrifuged at $5.000 \mathrm{~g}$ for $10 \mathrm{~min}$ at $4^{\circ} \mathrm{C}$ and the supernatant discarded. 2,4-dinitrophenylhydrazine (10 mM DNPH) (Sigma-Aldrich) diluted in $2 \mathrm{mM}$ hydrochloric acid was added to the test pellet. When white is added only $\mathrm{HCl} 2 \mathrm{mM}$. The samples were kept in the dark at room temperature for $30 \mathrm{~min}$ and homogenized in Vortex every $15 \mathrm{~min}$. After, $10 \%$ trichloroacetic acid was added to the samples, which were homogenized and centrifuged at $5.000 \mathrm{~g}$ for $10 \mathrm{~min}$ at $4^{\circ} \mathrm{C}$. The supernatant was discarded, and the pellet washed in $1 \mathrm{~mL}$ of ethanol and ethyl acetate (1:1) and centrifuged at $5.000 \mathrm{~g}$ for $10 \mathrm{~min}$ and at $4^{\circ} \mathrm{C}$ twice. Finally, the pellet was dissolved in $6 \%$ sodium dodecyl sulfate and centrifuged at $10.000 \mathrm{~g}$ for $10 \mathrm{~min}$ at $4{ }^{\circ} \mathrm{C}$. The supernatant was evaluated in a spectrophotometer at $370 \mathrm{~nm}$ (SpectraMax 190, Molecular Devices). A molar absorption coefficient of $22.000 \mathrm{M} / \mathrm{cm}$ was considered (Dalle-Donne et al., 2003; Levine et al., 1994).

\section{Superoxide dismutase activity}

The test of superoxide dismutase activity (EC 1.15.1.1) was performed according to Del Maestro and McDonald (1987) and as described by Barreto et al. (2012). Samples from each gastrocnemius $(0.03 \mathrm{~mL})$ and tibial anterior $(0.1 \mathrm{~mL})$ tissue were added to $0.6 \mathrm{~mL}$ potassium phosphate buffer $\left(50 \mathrm{mM}, \mathrm{pH} 8.2,37^{\circ} \mathrm{C}\right)$ containing $1 \mathrm{mM}$ DTPA (diethylenetriamine penta-acetic acid) (Sigma-Aldrich). The reaction started by adding $0.003 \mathrm{~mL}$ of pyrogallol (1,2,3-benzenetriol, Sigma-Aldrich) to $0.2 \mathrm{mM}$. The reaction was determined by spectrophotometer on a microplate reader at $420 \mathrm{~nm}, 37^{\circ} \mathrm{C}$, for $4 \mathrm{~min}$ (SpectraMax 190, Molecular Devices). The activity of superoxide dismutase was expressed as U/mg protein, where one unit of enzyme is the amount that causes inhibition of autoxidation of pyrogallol by $50 \%$.

\section{Catalase activity}

The catalase activity test (EC 1.11.1.6) was performed as described by Barreto et al. (2012). The following were added: 0.7 $\mathrm{mL}$ of phosphate buffer $(50 \mathrm{mM}, \mathrm{pH} 7.0)$ and an aliquot of 0.015 $\mathrm{mL}$ gastrocnemius and $0.025 \mathrm{~mL}$ tibial anterior of the homogenate, and then added gastrocnemius $(0.02 \mathrm{~mL})$ and tibial anterior $(0.01 \mathrm{~mL})$ of substrate $\left(\mathrm{H}_{2} \mathrm{O}_{2}, 0.03 \mathrm{M}\right)$ (Sigma-Aldrich). The hydrogen peroxide decline was performed for $1 \mathrm{~min}$ at $25^{\circ} \mathrm{C}$ in a spectrophotometer at $240 \mathrm{~nm}$ (Libra S22 spectrophotometer, Biochrom, UK) in quartz cuvettes. The catalase was expressed as $\Delta \mathrm{E} /$ $\mathrm{min} / \mathrm{mg}$ protein, where $\Delta \mathrm{E}$ corresponds to the variation of enzyme activity for $1 \mathrm{~min}$.

\section{Non-enzymatic antioxidant capacity}

The non-enzymatic antioxidant capacity of the samples was determined by the total antioxidant capacity method Benzie and Strain (1996). To a $0.528 \mathrm{~mL}$ aliquot of the total antioxidant capacity reagent, $0.072 \mathrm{~mL}$ of the sample homogenate was added. This mixture was homogenized and incubated in the dark at $37^{\circ} \mathrm{C}$ for $30 \mathrm{~min}$. The samples were then centrifuged at $300 \mathrm{~g}$ for $5 \mathrm{~min}$ and the supernatant was spectrophotometrically analyzed in a microplate reader at $593 \mathrm{~nm}$ (SpectraMax 190, Molecular Devices). The total antioxidant capacity of the samples was expressed as $\mathrm{Fe}^{2+}$ equivalents, determined from the standard curve of known concentrations of $\mathrm{FeSO}_{4}$ and normalized by the amount of protein in the sample. The results were expressed as $\mu \mathrm{M} \mathrm{FeSO}_{4} /$ mg protein.

\section{Dosage of proteins}

The protein concentration of the samples was determined by the method of Bradford quantification (Comassie blue assay) (Bradford, 1976). The duplicate reading was performed on the 
spectrophotometer in a microplate reader (SpectraMax 190, Molecular Devices) at $590 \mathrm{~nm}$ and the protein values determined by Softmaxpro Software (ver. 5.4, Molecular Devices) in $\mathrm{mg} / \mathrm{mL}$.

\section{Statistical analysis}

The descriptive statistical analysis was performed via mean and standard deviation calculations to intramuscular collagen fiber quantification, markers of oxidative damage (thiobarbituric reactive substances and Carbonyl derivatives in proteins) and antioxidant defense (superoxide dismutase, catalase and total antioxidant capacity). For the analysis of oxidative damage and antioxidant defenses, mean values of the WT group were used to normalize the values of $m d x \mathrm{~T}$ and $m d x \mathrm{NT}$ groups. Analysis of the normality of the data was performed by the Shapiro-Wilk test. To detect difference between groups, the analysis of variance was performed and the Bonferroni test was used as post hoc. The variables which were normally distributed were analyzed by independent $t$-test and the variables not normally distributed were analyzed by the Mann-Whitney $U$-test. Correlation analysis was performed using Pearson correlation coefficient and Spearman correlation coefficient tests according to the distribution of normality of the samples. Correlations were considered weak to values less than 0.50 , moderate 0.50 to 0.75 , strong 0.75 to 0.90 , very strong when greater than 0.90 (Koo and Li, 2016). The IBM SPSS Statistics ver. 19.0 (IBM Co., Armonk, NY, USA) was used for data analysis, considering $P \leq 0.05$.

\section{RESULTS}

Qualitative analysis of tibial anterior and gastrocnemius muscles showed that collagen fibers are organized in thick tracts mainly of perimysium and thin bundles in the endomysium. The $m d x \mathrm{~T}$ group presented thinner bundles of perimysium covering larger muscular areas when compared to $m d x \mathrm{NT}$. Collagen fibers of WT animals are organized in thin tracts of perimysium and endomysium as shown in Figs. 1 and 2.

\section{Intramuscular collagen deposition}

Gastrocnemius and tibial anterior muscle morphometry of collagen fibers deposition showed similar features. The percentage area of intramuscular collagen fibers deposition of the $m d x \mathrm{NT}$ group (4.26 \pm 3.3$)$ was higher than the $m d x \mathrm{~T}(1.75 \pm 0.9)$ and WT $(1.13 \pm 1.1)(P=0.025)$ groups to gastrocnemius muscle. Tibial anterior muscle percentage area was also higher in the $m d x \mathrm{NT}$ group $(0.70 \pm 0.2)$ than $m d x \mathrm{~T}(0.31 \pm 0.1)$ and WT $(0.30 \pm 0.1)$ $(P=0.000)$. No significant difference could be observed between mean values of $m d x \mathrm{~T}$ and $\mathrm{WT}$ groups for gastrocnemius $(P=1)$ or tibial anterior $(P=1)$ analysis (Fig. 3).
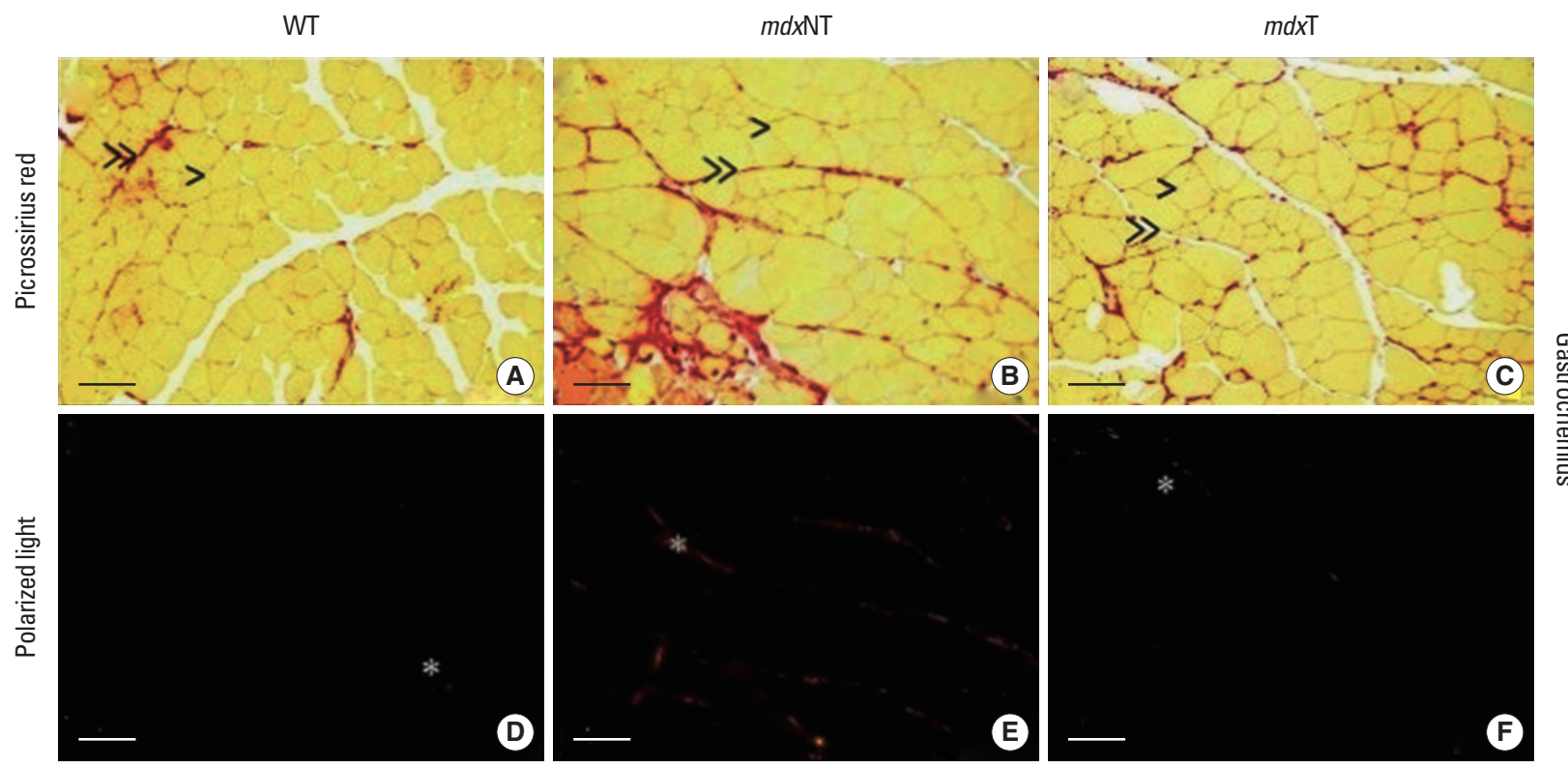

Fig. 1. Morphological analysis of the deposition of collagen fibers on gastrocnemius muscle. Picrossirius red reaction (A-C) and picrossirius red under polarized light (D-F). Scale bar $=200 \mu \mathrm{m}$. WT, wild-type; $m d x T$, trained $m d x$ animals; $m d x N T$, untrained $m d x$ animals. `'Deposition of collagen fibers in the perimysium. 'Deposition of collagen fibers in endomysium. *Deposition of collagen fibers in polarized light. 

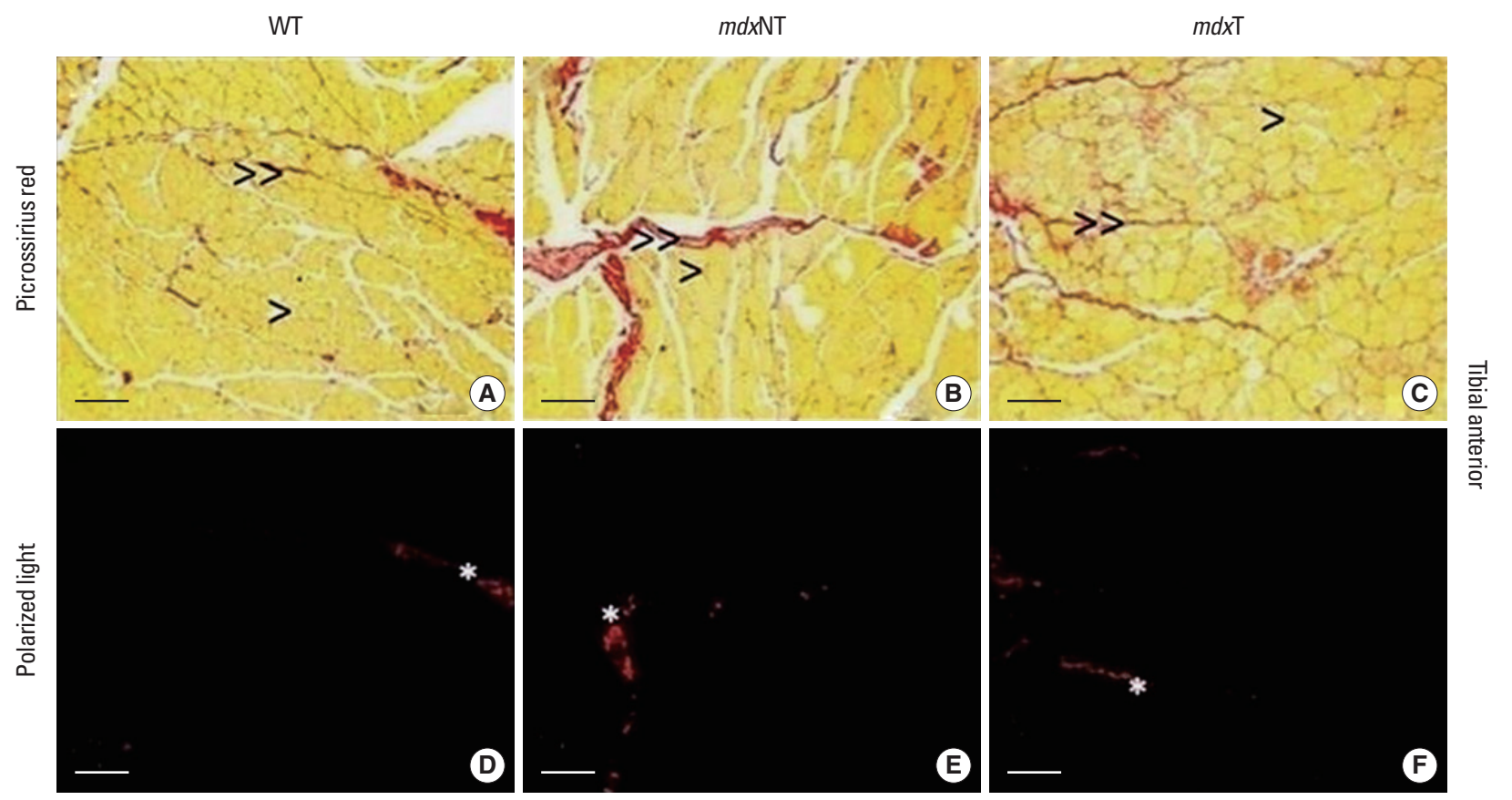

Fig. 2. Morphological analysis of the deposition of collagen fibers on tibial anterior muscle. Picrossirius red reaction (A-C) and picrossirius red under polarized light (DF). Scale bar $=200 \mu \mathrm{m}$. WT, wild-type; $m d x T$, trained $m d x$ animals; $m d x N T$, untrained $m d x$ animals. Anterior »Deposition of collagen fibers in the perimysium. 'Deposition of collagen fibers in endomysium. *Deposition of collagen fibers in polarized light.

TA

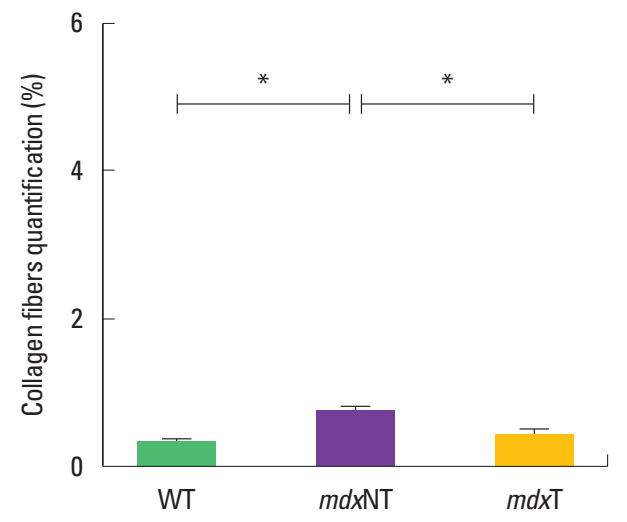

GASTROC

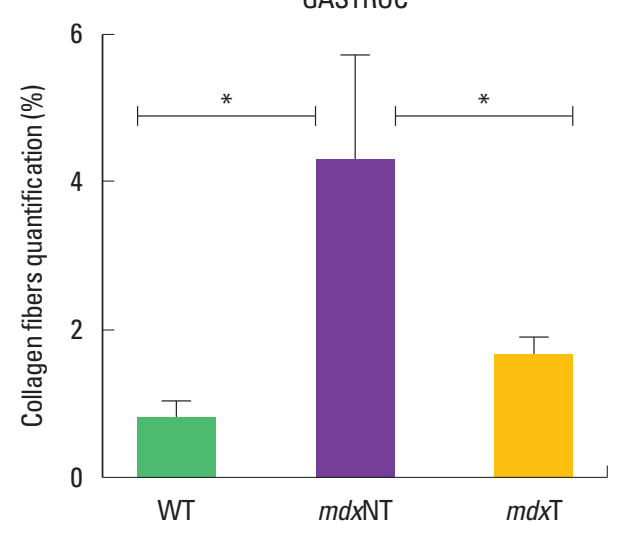

Fig. 3. Effect of low-intensity training on the percentage of intramuscular collagen fibers deposition. Morphometric analysis of the percentage of intramuscular collagen fiber deposition in tibial anterior and gastrocnemius muscles. TA, tibial anterior; GASTROC, gastrocnemius; WT, wild-type; $m d x T$, trained $m d x$ animals; $m d x N T$, untrained $m d x$ animals. *Significant difference between groups (analysis of variance one-way with post hoc Bonferroni test, $\mathrm{n}=21$ ).

\section{Markers of oxidative stress analysis}

Concentration of oxidative stress markers (thiobarbituric reactive substances and carbonyl derivatives in proteins) were higher in the $m d x \mathrm{~T}$ group when compared to $m d x \mathrm{NT}$ or WT groups for gastrocnemius and tibial anterior muscles.

Mean values of thiobarbituric reactive substances on tibial anterior and gastrocnemius muscles were higher in the $m d x \mathrm{~T}$ group
$(1.24 \pm 0.2$ and $1.36 \pm 0.4)$ than the $m d x \mathrm{NT}$ group $(0.83 \pm 0.0$ and $0.75 \pm 0.1)(P=0.005$ for gastrocnemius and $P=0.013$ for tibial anterior), respectively. Carbonyl derivatives in proteins concentration in gastrocnemius and tibial anterior were higher in the $m d x \mathrm{~T}$ group (1.66 \pm 0.3 and $1.40 \pm 0.6)$ than $m d x \mathrm{NT}(0.85 \pm 0.1$ and $1.40 \pm 0.6)(P=0.004$ for gastrocnemius and $P=0.019$ for tibial anterior analysis) (Fig. 4, Table 1). 

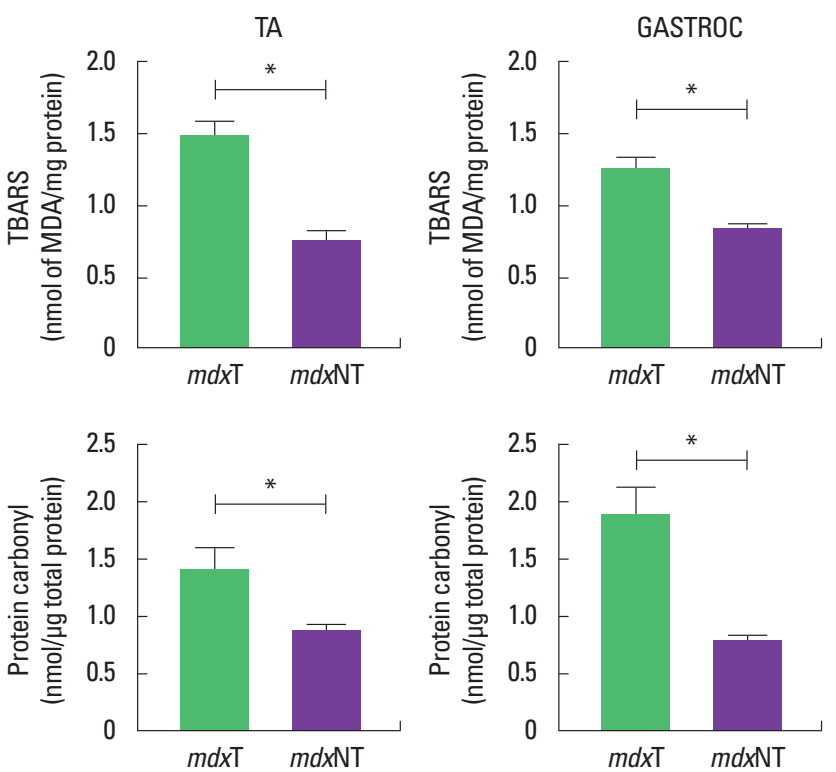

Fig. 4. Effect of low-intensity training on markers of oxidative damage in muscles. Concentration of malondialdehyde in tibial anterior and gastrocnemius muscles. Concentration of carbonyl compounds in the tibial anterior and gastrocnemius muscles. TA, tibial anterior; GASTROC, gastrocnemius; $m d x T$, trained $m d x$ animals; $m d x N T$, untrained $m d x$ animals. ${ }^{*}$ Significant difference between groups (independent $t$-test or Mann-Whitney U-test, $\mathrm{n}=21$ ).

Table 1. Concentration ratio of muscle damage markers of dystrophic animals normalized by wild-type

\begin{tabular}{lcccccc}
\hline & \multicolumn{2}{c}{ TBARS } & & \multicolumn{2}{c}{ Carbonyl derivatives } \\
\cline { 2 - 3 } \cline { 5 - 7 } & $m d x T$ & $m d x N T$ & & $m d x T$ & $m d x N T$ \\
\hline Tibial anterior & 1.36 & 0.75 & & 1.40 & 0.87 \\
Gastrocnemius & 1.24 & 0.83 & & 1.66 & 0.85
\end{tabular}

TBARS, thiobarbituric reactive substances; $m d x$, trained $m d x$ animals; $m d x N$, untrained $m d x$ animals.

\section{Antioxidant enzyme system analysis}

Superoxide dismutase activity was similar to gastrocnemius muscle in both $m d x$ groups $(P=0.306)$, with $m d x \mathrm{~T}$ group $(1.10 \pm$ 0.4 ) presenting $28.8 \%$ higher activity than $m d x \mathrm{NT}$ group $(0.81 \pm 0.1)$. At tibial anterior muscle superoxide dismutase activity was higher in the $m d x \mathrm{~T}$ group $(0.98 \pm 0.1)$ than the $m d x \mathrm{NT}$ group $(0.65 \pm 0.0)(P=0.003)$.

Catalase presented no difference between the studied muscles or animal groups. Even though its activity was $47.4 \%$ higher on the $m d x \mathrm{~T}$ group (1.20 \pm 0.9$)$ than the $m d x \mathrm{NT}$ group $(0.72 \pm 0.3)$, there was no significant difference between them with regard to gastrocnemius muscle $(P=0.323)$. Regarding tibial anterior muscle analysis, catalase activity was $15.6 \%$ higher in the $m d x \mathrm{~T}$ group $(0.95 \pm 0.3)$ when compared to $m d x$ NT $(0.81 \pm 0.3)(P=0.527)$.
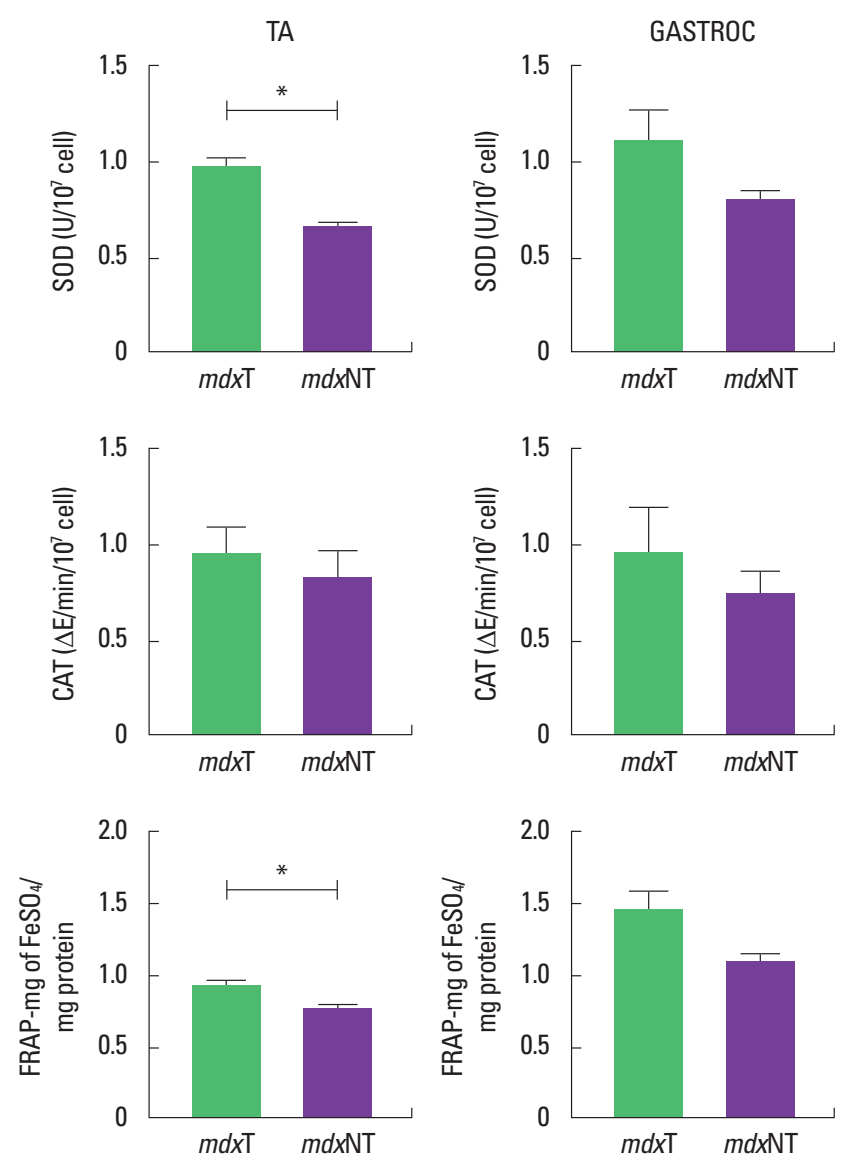

Fig. 5. Effect of low-intensity training on the antioxidant defense of muscles. Activity of the superoxide dismutase (SOD), catalase (CAT), and ferric reducing ability of plasma (FRAP) in tibial anterior and gastrocnemius muscles. TA, tibial anterior; GASTROC, gastrocnemius; $m d x T$, trained $m d x$ animals; $m d x N T$, untrained $m d x$ animals. *Significant difference between groups (independent t-test or Mann-Whitney U-test, $\mathrm{n}=21$ ).

Table 2. Concentration ratio of antioxidants of dystrophic animals normalized by wild-type

\begin{tabular}{|c|c|c|c|c|c|c|}
\hline & \multicolumn{2}{|c|}{ SOD } & \multicolumn{2}{|c|}{ САТ } & \multicolumn{2}{|c|}{ FRAP } \\
\hline & $m d x \top$ & $m d x N T$ & $m d x \top$ & $m d x \mathrm{NT}$ & $m d x \top$ & $m d x N T$ \\
\hline Tibial anterior & 0.98 & 0.70 & 0.95 & 0.81 & 0.90 & 0.74 \\
\hline Gastrocnemius & 1.10 & 0.86 & 1.20 & 0.72 & 1.45 & 1.09 \\
\hline
\end{tabular}

SOD, superoxide dismutase; CAT, catalase; FRAP, ferric reducing ability of plasma; $m d x T$, trained $m d x$ animals; $m d x N T$, untrained $m d x$ animals.

Total antioxidant capacity of the gastrocnemius muscle was similar to $m d x \mathrm{~T}(1.45 \pm 0.4)$ and $m d x \mathrm{NT}$ groups $(1.09 \pm 0.1)$ $(P=0.110)$, with the trained group presenting $35.9 \%$ more antioxidant capacity than the untrained group. For the tibial anterior muscle this activity was significantly higher in the trained group $(0.90 \pm 0.0)$ than the $m d x$ NT group $(0.74 \pm 0.1)(P=0.024)$, as 
TA
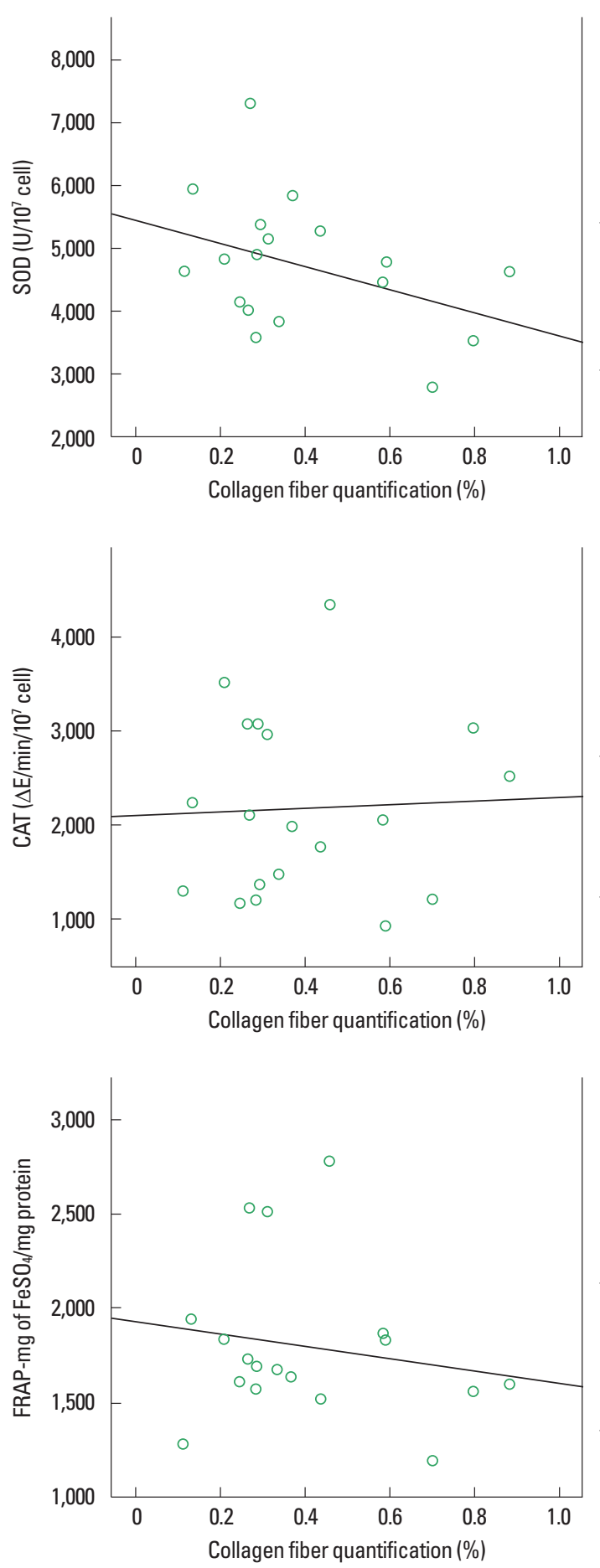

GASTROC
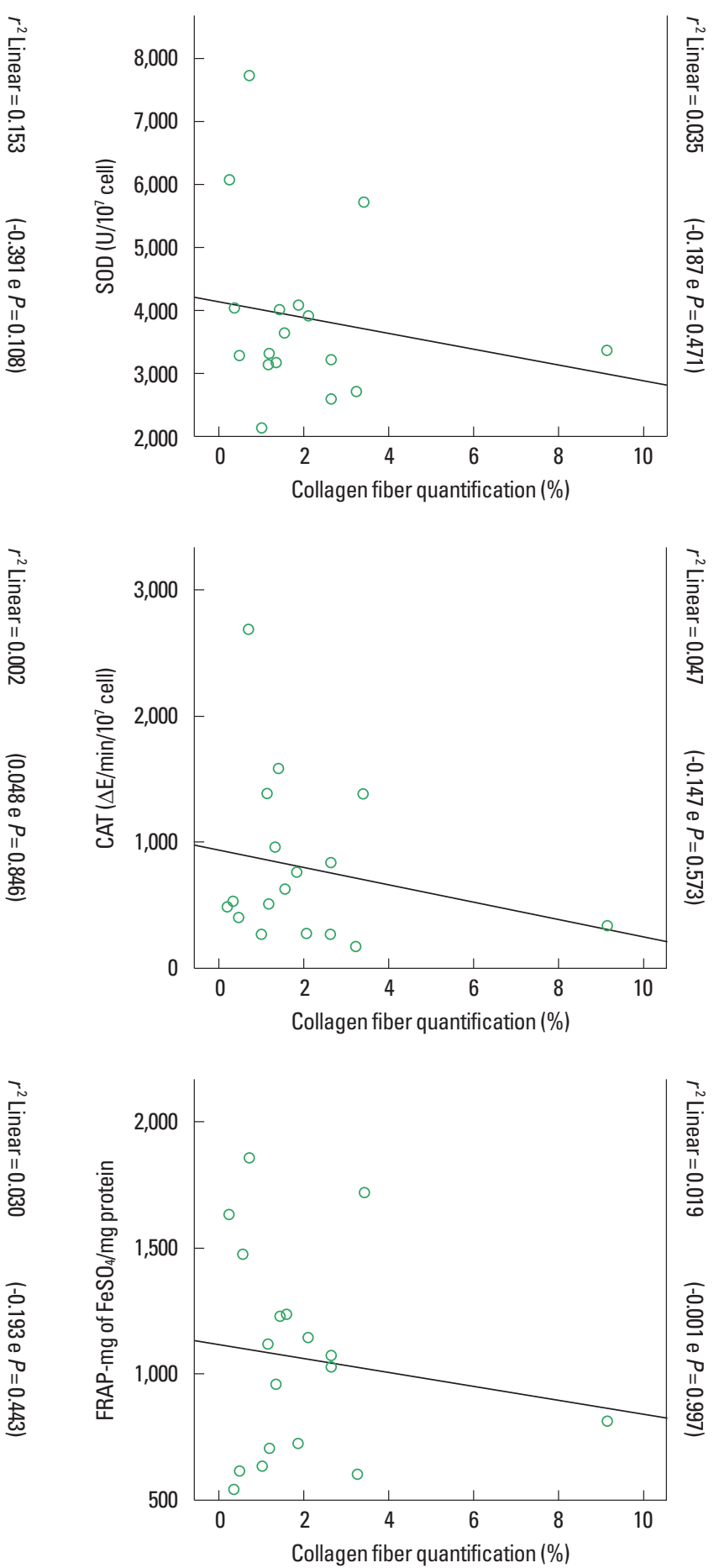

Fig. 6. Correlation between deposition of collagen fibers and antioxidants after low-intensity training. Analysis of the correlation between collagen fiber deposition and superoxide dismutase (SOD), catalase (CAT), and ferric reducing ability of plasma (FRAP) on tibial anterior and gastrocnemius muscles. The value of $r^{2}$ Linear is expressed at the figure. TA, tibial anterior; GASTROC, gastrocnemius.

shown in (Fig. 5).

Table 2 shows that the activity of superoxide dismutase and to- tal antioxidant capacity were perceptually higher in the trained group compared to the untrained one. 


\section{Antioxidant system $x$ collagen fiber deposition correlation}

The correlation between antioxidant system values and collagen fiber deposition showed values that are considered weak with no statistical significance. Values of the correlation and $r^{2}$ are shown in (Fig. 6). Even then, it is possible to observe that the correlation was always negative showing that there is an inverse proportion among these analyzed variables.

\section{DISCUSSION}

The muscle groups of $m d x$ mice are differently affected by the absence of dystrophin: hindlimb muscles show more necrosis than diaphragm but little fibrosis after the regeneration process. For this reason, it is recommended to investigate more than one single muscle to understand the effects of an intervention (Hyzewicz et al., 2015a).

Gastrocnemius and tibial anterior are both hindlimb muscles, but they present different fiber type distribution (Grounds et al., 2008; Qaisar et al., 2016) and function on the biomechanics of the gait (Baltgalvis et al., 2012), which impacts on their response to injury induced by exercise. In general, gastrocnemius is affected in horizontal treadmill training as it has more type II fiber (Hyzewicz et al., 2015b) and slow-twitch oxidative (type I) muscle fibers demonstrating a higher antioxidant capacity than fast-twitch (type II) fibers (Gomez-Cabrera et al., 2009). Low-intensity training provoked the same adaptation in the deposition of collagen fibers in the anterior tibial and gastrocnemius muscle of the $m d x$ mice, but presented higher mean values of connective tissue infiltration in the gastrocnemius muscle. Although the studied muscles had a greater amount of type II fibers, the tibial anterior muscle had a better performance of antioxidant defenses than the gastrocnemius muscle which is probably due to its gait function.

According to Chapman et al. (2015) and Smith et al. (2016), the accumulation of collagen fibers on the extracellular matrix results in fibrosis. It is a significant clinical problem as it has an impact on the normal cellular function, strength transmission among muscle fibers and inhibits the process of repair and regeneration, perpetuating the chronic damage due to the absence of dystrophin.

The histopathological analysis of both muscles had their features confirmed by the morphometric analysis of the intramuscular collagen fiber deposition. Low-intensity training decreased intramuscular collagen fiber deposition on the trained dystrophic animals with values getting near to the ones of the control animals.
The fibrosis deposition reflects the final step of an aberrant repair of the dystrophic skeletal muscle (Hardy et al., 2016; Mann et al., 2011), and training protocols that increase the fibrosis deposition are considered deleterious to dystrophic muscles as in the case of Barreto et al. (2012) who employed the high intensity training protocol of $30 \mathrm{~min} /$ day, every day for 4 weeks at a speed of 12 $\mathrm{m} / \mathrm{min}$.

Hyzewicz et al. (2015a) stated that the formation of fibrosis occurs after the tenth week of age of the $m d x$ mice. The low intensity protocol employed here initiated when the animals were eleven weeks old which seems that the training reduced the fibrosis deposition, positively repairing the extracellular matrix as the trained group presented lower collagen fiber deposition when compared to the untrained ones which means that this training intensity and modality had a positive impact on muscle function.

The level of activity is highly related to the physiological features of skeletal muscle. Hourdé et al. (2013) showed that the inactivity promoted by hindlimb immobilization had worsened the muscle strength and increased the susceptibility of contraction-induced injury in the $m d x$ mice. They conclude that it can be improved through activity. This subtle threshold among activity and inactivity is still under investigation in preclinical models (Hyzewicz et al., 2015a) and humans DMD (Gianola et al., 2013).

The intensity of the exercise is an important point that influences the response of ROS. The increase of hydrogen peroxide is a signalization to stimulate the antioxidant enzymes synthesis. Due to the effects of ROS on positive regulation of antioxidant defense, moderate exercise can be seen as an antioxidant, even in muscular dystrophies (Gomez-Cabrera et al., 2009).

Existing publications of exercise and status redox on DMD usually focus on one single marker of the status redox. In order to make an inference about the ROS response on gastrocnemius and tibial anterior muscles of the $m d x$ mice submitted to low-intensity training, we have here analyzed catalase, superoxide dismutase, total antioxidant capacity to reflect the activity of antioxidant defense, thiobarbituric reactive substances (lipid peroxidation) and oxidation of proteins to reflect the concentration of the oxidative damage.

The increased level of MDA, final product of the lipid peroxidation, can be associated with the increased necrosis tissue which, according to Manning and O'Malley (2015), is observed after 12 and $48 \mathrm{hr}$ of voluntary exercise.

To Kozakowska et al. (2015), skeletal muscle cells have a sophisticated antioxidant enzymatic system which makes it extremely flexible to answer to the status redox alterations. Gastroc- 
nemius and tibial anterior muscles showed a similar response of the antioxidant enzyme system (superoxide dismutase, catalase and total antioxidant capacity) to the low intensity training. This increased activity of antioxidant enzymes is expected in response to a training protocol in a health muscle (Espinosa et al., 2016) as it induces a positive regulation of this antioxidant system, but little is known about the answer to the same system on dystrophic muscle.

The superoxide dismutase presents $28.8 \%$ higher activity on the tibial anterior muscle of trained animals when compared to untrained ones, but this increase of activity was not statistically significant. This same behavior was observed in a study of Kaczor et al. (2007) that investigated a low intensity training of 8 weeks on $m d x$ mice where superoxide dismutase activity on the gastrocnemius muscle was not modified with training. Superoxide dismutase activity is expected to increase in muscle tissue after exercise while catalase tends to remain unchanged (Moulin and Ferreiro, 2017).

According to Fontana et al. (2015), the low intensity resistance exercise can significantly recover superoxide dismutase levels in $m d x$ muscles suggesting that a specific training protocol can contribute to skeletal muscle repair promoting protection against oxidative stress.

Our muscle tissue collection was made $24 \mathrm{hr}$ after the last training protocol and, according to Kozakowska et al. (2015), the increase of catalase expression is usually late and has a peak of activity on day 2 after injury, which can explain the absence of change in this antioxidant enzyme.

The total antioxidant capacity was higher on the tibial anterior muscle of the trained animals. On the gastrocnemius muscle of trained animals this activity was $35.9 \%$ higher (but not significant) than the untrained animals. This increase in antioxidant enzymes was not sufficient in preventing lipidic peroxidation during the first $24 \mathrm{hr}$ after the protocol but their joint action can sustain the attenuation of intramuscular collagen fibers deposition on trained animals after 8 weeks of training.

A transitory oxidative stress on injured muscle cells is considered necessary to activate multiple signal transduction pathways relevant to complete muscle restoration. Prolonged oxidative stress can unbalance long-term intracellular antioxidant homeostasis of muscle cells (Barbieri and Sestili, 2012). Inflammatory process is intrinsically related to oxidative stress which is modified by exercise and seems to ameliorate status redox (Kostek and Gordon, 2018). Sies (2015) report it is still necessary to add new know on the relation of oxidative stress and inflammatory re- sponses.

The trained $m d x$ animals had a decreased intramuscular collagen fibers deposition influenced by low intensity training, and muscular damage seems to have been lessened by the antioxidants that presented an increase in their activity. Treadmill low intensity training is beneficial to the hindlimb dystrophic muscle as it improved the status redox through the increased activity of antioxidant defense and reduction of collagen fibers deposition of the $m d x$ model.

\section{CONFLICT OF INTEREST}

No potential conflict of interest relevant to this article was reported.

\section{ACKNOWLEDGMENTS}

The authors thank to FAPEMIG (Minas Gerais State Agency for Research and Development) by the financial support of the process number APQ-01971-12.

\section{REFERENCES}

Baltgalvis KA, Call JA, Cochrane GD, Laker RC, Yan Z, Lowe DA. Exercise training improves plantar flexor muscle function in $\mathrm{mdx}$ mice. Med Sci Sports Exerc 2012;44:1671-1679.

Barbieri E, Sestili P. Reactive oxygen species in skeletal muscle signaling. J Signal Transduct 2012;2012:982794.

Barreto TO, Cleto LS, Gioda CR, Silva RS, Campi-Azevedo AC, de Sousa-Franco J, de Magalhães JC, Penaforte CL, Pinto KM, Cruz Jdos S, Rocha-Vieira E. Swim training does not protect mice from skeletal muscle oxidative damage following a maximum exercise test. Eur J Appl Physiol 2012;112:2523-2530.

Benzie IF, Strain JJ. The ferric reducing ability of plasma (FRAP) as a measure of "antioxidant power": the FRAP assay. Anal Biochem 1996;239: 70-76.

Bradford MM. A rapid and sensitive method for the quantitation of microgram quantities of protein utilizing the principle of protein-dye binding. Anal Biochem 1976;72:248-254.

Chapman MA, Pichika R, Lieber RL. Collagen crosslinking does not dictate stiffness in a transgenic mouse model of skeletal muscle fibrosis. J Biomech 2015;48:375-378.

Chazaud B. Inflammation during skeletal muscle regeneration and tissue remodeling: application to exercise-induced muscle damage management. Immunol Cell Biol 2016;94:140-145. 
Comim CM, Hoepers A, Ventura L, Freiberger V, Dominguini D, Mina F, Mendonça BP, Scaini G, Vainzof M, Streck EL, Quevedo J. Activity of Krebs cycle enzymes in mdx mice. Muscle Nerve 2016;53:91-95.

Dalle-Donne I, Giustarini D, Colombo R, Rossi R, Milzani A. Protein carbonylation in human diseases. Trends Mol Med 2003;9:169-176.

De Luca A. DMD_M.2.1.001: Use of treadmill and wheel exercise for impact on mdx mice phenotype 2014 [Internet]. Washington, DC: Wellstone Muscular Dystrophy Center; 2014 March [cited 2017 Mar 15]. Available from: http://www.treat-nmd.eu/downloads/file/sops/dmd/ MDX/DMD_M.2.1.001.pdf.

Del Maestro R, McDonald W. Distribution of superoxide dismutase, glutathione peroxidase and catalase in developing rat brain. Mech Ageing Dev 1987;41:29-38.

Espinosa A, Henríquez-Olguín C, Jaimovich E. Reactive oxygen species and calcium signals in skeletal muscle: a crosstalk involved in both normal signaling and disease. Cell Calcium 2016;60:172-179.

Fontana S, Schillaci O, Frinchi M, Giallombardo M, Morici G, Di Liberto V, Alessandro R, De Leo G, Perciavalle V, Belluardo N, Mudò G. Reduction in $\mathrm{mdx}$ mouse muscle degeneration by low-intensity endurance exercise: a proteomic analysis in quadriceps muscle of exercised compared with sedentary mdx mice. Biosci Rep 2015;35(3). pii: e00213. https://doi.org/10.1042/BSR20150013.

Frinchi M, Macaluso F, Licciardi A, Perciavalle V, Coco M, Belluardo N, Morici G, Mudò G. Recovery of damaged skeletal muscle in $\mathrm{mdx}$ mice through low-intensity endurance exercise. Int J Sports Med 2014;35: 19-27.

Gaiad TP, Oliveira MX, Lobo AR Jr, Libório LR, Pinto PA, Fernandes DC, Santos AP, Ambrósio CE, Machado AS. Low-intensity training provokes adaptive extracellular matrix turnover of a muscular dystrophy model. J Exerc Rehabil 2017;13:693-703.

Gianola S, Pecoraro V, Lambiase S, Gatti R, Banfi G, Moja L. Efficacy of muscle exercise in patients with muscular dystrophy: a systematic review showing a missed opportunity to improve outcomes. PLoS One 2013;8:e65414.

Gomez-Cabrera MC, Viña J, Ji LL. Interplay of oxidants and antioxidants during exercise: implications for muscle health. Phys Sportsmed 2009; 37:116-123.

Grounds MD, Radley HG, Lynch GS, Nagaraju K, De Luca A. Towards developing standard operating procedures for pre-clinical testing in the mdx mouse model of Duchenne muscular dystrophy. Neurobiol Dis 2008;31:1-19.

Hardy D, Besnard A, Latil M, Jouvion G, Briand D, Thépenier C, Pascal Q Guguin A, Gayraud-Morel B, Cavaillon JM, Tajbakhsh S, Rocheteau P, Chrétien F. Comparative study of injury models for studying muscle regeneration in mice. PLoS One 2016;11:e0147198.
Hourdé C, Joanne P, Medja F, Mougenot N, Jacquet A, Mouisel E, Pannerec A, Hatem S, Butler-Browne G, Agbulut O, Ferry A. Voluntary physical activity protects from susceptibility to skeletal muscle contraction-induced injury but worsens heart function in mdx mice. Am J Pathol 2013;182:1509-1518.

Hyzewicz J, Ruegg UT, Takeda S. Comparison of experimental protocols of physical exercise for mdx mice and duchenne muscular dystrophy patients. J Neuromuscul Dis 2015a;2:325-342.

Hyzewicz J, Tanihata J, Kuraoka M, Ito N, Miyagoe-Suzuki Y, Takeda S. Low intensity training of $\mathrm{mdx}$ mice reduces carbonylation and increases expression levels of proteins involved in energy metabolism and muscle contraction. Free Radic Biol Med 2015b;82:122-136.

Kaczor JJ, Hall JE, Payne E, Tarnopolsky MA. Low intensity training decreases markers of oxidative stress in skeletal muscle of $\mathrm{mdx}$ mice. Free Radic Biol Med 2007;43:145-154.

Kim JH, Kwak HB, Thompson LV, Lawler JM. Contribution of oxidative stress to pathology in diaphragm and limb muscles with Duchenne muscular dystrophy. J Muscle Res Cell Motil 2013;34:1-13.

Klingler W, Jurkat-Rott K, Lehmann-Horn F, Schleip R. The role of fibrosis in Duchenne muscular dystrophy. Acta Myol 2012;31:184-195.

Koo TK, Li MY. A Guideline of selecting and reporting intraclass correlation coefficients for reliability research. J Chiropr Med 2016;15:155-163.

Kostek MC, Gordon B. Exercise is an adjuvant to contemporary dystrophy treatments. Exerc Sport Sci Rev 2018;46:34-41.

Kozakowska M, Pietraszek-Gremplewicz K, Jozkowicz A, Dulak J. The role of oxidative stress in skeletal muscle injury and regeneration: focus on antioxidant enzymes. J Muscle Res Cell Motil 2015;36:377-393.

Levine RL, Williams JA, Stadtman ER, Shacter E. Carbonyl assays for determination of oxidatively modified proteins. Methods Enzymol 1994; 233:346-357.

Mann CJ, Perdiguero E, Kharraz Y, Aguilar S, Pessina P, Serrano AL, Muñoz-Cánoves P. Aberrant repair and fibrosis development in skeletal muscle. Skelet Muscle 2011;1:21.

Manning J, O'Malley D. What has the mdx mouse model of Duchenne muscular dystrophy contributed to our understanding of this disease? J Muscle Res Cell Motil 2015;36:155-167.

Moulin M, Ferreiro A. Muscle redox disturbances and oxidative stress as pathomechanisms and therapeutic targets in early-onset myopathies. Semin Cell Dev Biol 2017;64:213-223.

Ohkawa H, Ohishi N, Yagi K. Assay for lipid peroxides in animal tissues by thiobarbituric acid reaction. Anal Biochem 1979;95:351-358.

Pérez-Torres I, Guarner-Lans V, Rubio-Ruiz ME. Reductive stress in inflammation-associated diseases and the pro-oxidant effect of antioxidant agents. Int J Mol Sci 2017;18:E2098

Qaisar R, Bhaskaran S, Van Remmen H. Muscle fiber type diversification 
during exercise and regeneration. Free Radic Biol Med 2016;98:56-67.

Schill KE, Altenberger AR, Lowe J, Periasamy M, Villamena FA, Rafael-

Fortney JA, Devor ST. Muscle damage, metabolism, and oxidative

stress in mdx mice: impact of aerobic running. Muscle Nerve 2016;

54:110-117.

Sies H. Oxidative stress: a concept in redox biology and medicine. Redox Biol 2015;4:180-183.

Smith LR, Barton ER. Collagen content does not alter the passive mechanical properties of fibrotic skeletal muscle in mdx mice. Am J Physiol Cell Physiol 2014;306:C889-898.

Smith LR, Hammers DW, Sweeney HL, Barton ER. Increased collagen cross-linking is a signature of dystrophin-deficient muscle. Muscle Nerve 2016;54:71-78.

van Putten M, Hulsker M, Nadarajah VD, van Heiningen SH, van Huizen

E, van Iterson M, Admiraal P, Messemaker T, den Dunnen JT, 't Hoen

PA, Aartsma-Rus A. The effects of low levels of dystrophin on mouse muscle function and pathology. PLoS One 2012;7:e31937.

Zanotti S, Bragato C, Zucchella A, Maggi L, Mantegazza R, Morandi L, Mora M. Anti-fibrotic effect of pirfenidone in muscle derived-fibroblasts from Duchenne muscular dystrophy patients. Life Sci 2016;145: 127-136. 